This document has been downloaded from TamPubuta.fi The Institutional Repository of University of Tampere

\title{
Representations of prostitutes and prostitution as a metaphor in nineteenth-century English newspapers
}

\author{
Marianna Hintikka and Minna Nevala
}

\begin{abstract}
In this article, we study the way in which prostitutes, on the one hand, and prostitution, on the other, were evaluated and represented in nineteenth-century English news articles. The main aims of the study are to chart referential terms used of prostitutes as socially marginal agents and objects, as well as to map concepts related to the metaphorical field of prostitution. Our data come from the 19th Century British Library Newspapers Database and The Times Digital Archive, consisting of altogether 300 news articles relating to prostitution. Our results suggest that there is variation between vilification and pity in the language relating to prostitutes in the Victorian press, both from the socio-pragmatic and the cognitive perspectives. While the overall attitudes are mostly negative, there is a tendency to highlight the humanity of the prostitute by referring to her, for example, as a pitiful object of a crime. All the metaphors found in the material also draw from the negativity seen as inherent in prostitution and prostitutes. This is accentuated by the frequent personification of states or political institutions as prostitutes, whose lamentable behaviour or appearance is referred to in the metaphor.
\end{abstract}

Keywords: linguistic representation, evaluative person reference, conceptual metaphors, Victorian press

\section{Introduction}

In the nineteenth century the information contents of the popular press were often mixed with entertaining characteristics, and newspapers feasted on the corruption of the social margins in particular (Conboy 2010). Much like today, these margins and their membership were staple headline material well suited for the pursuit of commercial success of certain kinds of publication. One way of defining what these social margins were and how they were evaluated is to look at how the members of the lowest classes were linguistically described.

In this article, we will study the lexico-semantic field of prostitution and focus on the conceptual relations between terms used of actual prostitutes, on the one hand, and metaphorically related concepts in certain, relevant fields of social discourse in England during the nineteenth century, on the other. Our aims are to look at a set of terms used for prostitutes and to determine how and to what extent these culturally mediated vehicles map conceptual parallelisms within the larger social network of value relations. We will therefore look at the relevant terminology (terms denoting 'prostitute') as cognitive source domain concepts and study the kinds of target domains they are mapped onto. We will also study the terms from a socio-pragmatic perspective by looking at how the social status and character of these "fallen women" are expressed in public writings of the time.

Our results suggest variation between vilification and pity in the language relating to prostitutes in the press, both from the socio-pragmatic and the cognitive perspectives. While the overall attitudes can only be identified as negative, there is a tendency to highlight the humanity of the prostitute, albeit at the expense of her agency, in the period studied. The study thus serves as a continuation to our previous research on the semantic and pragmatic variation and change in the terms used of common prostitutes in early and late modern England (Nevala and Hintikka 2009). In the previous study, we already found a notable change in the type of terminology used for prostitutes from the seventeenth to the eighteenth century: whereas in the 
earlier data prostitutes were mainly described as a great social evil to be despised, in the course of the eighteenth century they were increasingly seen as pitiful victims of the trade. ${ }^{1}$

In the following sections, we will first discuss background for our two main areas of research, evaluative person reference and cognitive metaphors, and then introduce and analyse our newspaper data. Lastly, we will draw some conclusions on the linguistic representation of prostitutes and prostitution as morally both detested and victimised entities.

\section{On the linguistic representation of prostitutes and prostitution}

\subsection{Representation and evaluative language on prostitutes}

Various representations of people are usually manifested in the so-called in-group and out-group discourse. Often the group we ourselves belong to becomes to be seen, and talked about, as the norm, 'us', and that of the other group as 'them'. When discussing the out-group, impoliteness, and negative labelling in particular, means creating and maintaining negative impressions, which can be aided or achieved through the use of 'labels of primary potency' (Allport 1986). This means that certain characteristics, like male/female or criminal/law-abiding, carry more perceptual potency than others, and signal difference from what is considered mainstream (e.g. moral distinctiveness). In other words, we evaluate other individuals and groups by labelling them one way or the other. These characteristics used for representation are structurally expressed in language use as, for example, adjectives and nouns, which can then be used as descriptive attributes and terms of reference. The descriptions, or linguistic evaluations, are often used first of an outgroup among a particular in-group, and can later on spread into common usage. (Allport 1986)

Linguistic evaluation carries an element of judgment, since when expressing, for example, our reluctance to be associated with a particular out-group, we simultaneously assess the characteristics of that group and all its members as negative. According to Bednarek (2006; see also Bednarek and Caple 2012), the judgment of whether something or someone is good or bad falls under the core parameter of emotivity. It is concerned with the expression of a person's approval or disapproval, and it can manifest itself in language in either positive (e.g. a polished speech) or negative (e.g. a rant) descriptions. It also contains an element of force from low intensity (a crime) and medium intensity (an assassination) to high intensity (a slaughter). She thus associates the scalarity of emotivity with that of objectivity, and admits that emotive meaning is difficult to recognise and categorise in general. (Bednarek 2006: 45-47). In Martin and White's (2005) appraisal theory, emotions both for and against are categorised under 'attitude'. 'Attitude' is in turn divided into three semantic dimensions, 'affect' (positive/negative feelings), 'judgment' (positive/negative attitude to behaviour), and 'appreciation' (positive/negative evaluation of semiotic and natural phenomena).

It is the notion of judgment that is the most central to the present study, since when describing, for example, a prostitute, we first and foremost evaluate that person through their behaviour and actions. Judgment also concerns ethic evaluation, what is right and what is wrong, and as a dimension of social sanction, it covers praise (descriptions like good, law-abiding, respectful) and condemnation (e.g. evil, corrupt, indecent). The division between positive and negative evaluation clearly reflects a more prevalent, societal attitude either in favour or against particular group memberships, as e.g. in the case of prostitution and prostitutes. The different definitions and descriptions related to prostitutes are, of course, a basis for creating and spreading stereotypes. By creating and using negative terms and attributes, 'respectable' people place prostitutes in a 'detestable' out-group. Images of grave diseases like cancer, plague and leprosy, or of filth, ugliness and

\footnotetext{
${ }^{1}$ For a further sociohistorical and corpuslinguistic discussion on the terminology of prostitutes, see e.g. McEnery and Baker (2016).
} 
beastliness, can be used to portray wrong-doers as a group outside the norms of society and at the bottom of the lowest social classes. Every time a prostitute is referred to as having negative attributes, other people are able to compare themselves with them, at the same time acknowledging and strengthening those positive qualities that make them a part of the major in-group that comprise the members of civil society (for more on imagery and terminology of disease and crime, see Nevala and Hintikka 2009, Nevala 2016).

Negative labelling then becomes a strategy based on the notion that no 'normal' person would be capable of such 'monstrous' act. In comparison, victims of negative action are often labelled positively. Tabbert (2015: 152) has found, for example, that in the press victims are often described in terms of their social network and environment, as well as their character. A victim whose identity is constructed as being loved and cared by others evokes more empathy and concern, because readers think s/he must be a 'good person' (2015: 104). The more people are affected, the more the impact of the act gets enhanced.

\subsection{Metaphor and cognitive embeddedness of prostitution as tools in argumentation}

Within cognitive linguistics and the various strands of what is commonly termed Cognitive Metaphor Theory (CMT) there is a widely shared agreement of the dual nature of many of the concepts we deal with, whether mundane or extraordinary (see Lakoff and Johnson 1980; Lakoff 1987; Kövecses 2000 etc.). What this means is that, according to CMT, people structure the world metaphorically, giving unfamiliar, less tangible, or abstract concepts names or tags derived from familiar domains in order to make them more accessible. The dual nature of these concepts, therefore, consists of the actual concept itself (the source domain), and all of the metaphorical extensions it can be associated with (the target domain), leading, in many cases, to polysemy and semantic extension of word meanings. The concepts of source and target domains provide a fruitful starting point for looking at the various cognitive associations between the concrete and the abstract elements of a single idea or idea cluster. In this paper we will look at the source domain of PROSTITUTION and chart the way in which it is mapped onto the target domain of SOCIETY in relevant parts.

The concept of SOCIETY - including all its subordinate categories - is a target domain drawing from a large number of source domains in many areas of discourse (Harris 1998; Musolff 2004, etc). In one of the most basic and perhaps the most historically established models, society is likened to a human body (the Body Politic), with all its parts and functions having counterparts in the human body (Lovejoy 1936; Tilliyard 1943). We can easily see multiple traces of this in contemporary discourse across languages, in emotively unmarked examples such as head of state, arm of the law, heart of the city, and so forth.

The further from the non-salient and ubiquitous we go, however, linguistic metaphors begin to acquire emotive and creative hues that carry ethical implications designed to influence their audience. This is, of course, in keeping with the above-mentioned association of objectivity with the presence or absence of emotiveness. To demonstrate the difference, we might look at a neutral concept like 'leg of a chair' and compare it to the somewhat less mundane cognitive metaphor of a WOMAN'S WAIST IS AN HOURGLASS. The former carries no perceivable emotive content and is, in fact, nearly indistinguishable as a metaphor, as we could hardly think of any other way to talk about the supporting structural elements of chairs. The concept of a LEG is therefore embedded within the domain of chairs as we actually form our understanding of CHAIRS as inherently possessing LEGS. On the other hand, we can easily think about women's waists without reference to hourglasses and the hourglass, while a pleasing analogy, is not instrumental to our understanding what a woman's waist is or what it looks like. This has a bearing when we look at the role of the metaphorical source concept of prostitution over the period studied. We will be looking at whether certain qualities associated with prostitutes are more likely than others to transcend the literal and become metaphorical in other discourse contexts. Such qualities include 'drunkenness', 'filthiness', 'fallenness', and 'ugliness', among others. Of these moral tags, 'fallenness' is the only one which rests (even if only partly) on sympathy, pity, or any such relatively compassionate attitude. The assumption is that the fixedness of an association plays a part in determining the emergent metaphorical potential of an expression (Zharikov and Gentner 2002: 976): apart from poetic, experimental, or stylistically contrived instances, metaphors do not 
tend to emerge on rarely used cognitive connections. In practice this means that, if we assume the association between prostitution and pitiability to be natural and strong, we would expect there to be metaphors that derive from this association.

Within the overall domain of SOCIETY, it is safe to say that its MARGINS form a sub-domain that is rife with creative metaphors deriving from a number of colorful source domains and/or mapped onto a number of different kinds of target domains. In this paper we look at a particular section of the social margins, namely, the domain of prostitutes and prostitution, which, for historical and obvious reasons, are among those concepts at the apex of emotive and creative metaphor use within social discourse. We will show how the concept of prostitution transcends the literal and makes for an established metaphorical bridge for the use of damning social or political discourse, and we will make note of the qualitative variation within these uses in the material.

Metaphorical patterns can be identified by looking for systematicity in structure mapping (Gentner 1983), through metaphor productivity and through metaphor extendedness (Hintikka 2013: 3-6), the first step of which is to identify the source and target domains involved - in the present case, terms for prostitutes, and topics of discussion, respectively. Two central aspects of patterns in metaphor are the notions of strength and productivity. To study metaphor strength we should look for repeated patterns of lexical co-occurrence, "i.e., words that tend to appear together in texts" (Svanlund 2007: 56). In the present material this would be realised through a cluster of prostitution-related items in a single context. These co-occurrences are called collocations, which are part of a syntagmatic relationship, or, in the words of Stubbs (2001: 30): "Collocation is a relation between words in a linear string." (Svanlund 2007: 57). Should the e.g. term prostitute, then, be accompanied by related terminology in close context, such as stew, brothel, punter, etc., it would be indicative that the term is metaphorically strong.

When many terms with similar meanings, i.e. words pertaining to the same conceptual field, are frequently used metaphorically, then that conceptual field can be said to be metaphorically productive (Svanlund 2007: 53). In the domain of prostitution this means that if many different items denoting the same thing (either 'prostitute' or 'prostitution') are frequently used as source concept in metaphor, then the domain can be said to be metaphorically productive.

Our argument is that lower productivity and higher strength tend to co-occur with embedded thought patterns. This means that a relatively limited range of frequently used metaphorical vocabulary tends to indicate underlying deep cognitive structures, whereas a thin layer (rare usage) of a highly varied vocabulary is a sign of linguistic inventiveness with no (necessarily) embedded cognitive basis. This claim is based on the observation that since a highly varied vocabulary is likely to consist of at least partly new metaphorical elements, the path toward semantic lexical change and therefore cognitive embeddedness is at its early stages, at best. We will show that, while the concept of PROSTITUTION is not particularly productive metaphorically in the present material (only three terms were found in metaphorical use), it is a fairly strong one (prostitution as a concept is often resorted to metaphorically in contexts having to do with other issues) and, as such, a cognitively embedded pattern of conceptual networking. This argument is supported by the significant extendedness exhibited by prostitution metaphors: particularly in the case of one of the terms studied, the metaphorical term for prostitute is significantly often extended to by a chain of discourseappropriate terms from adjacent source domains in order to form a source domain level 'narrative' structure loosely akin to allegory.

\section{Material and methods}

The material for the current study consists of 200 news features on prostitutes and prostitution from the 19th Century British Library Newspapers Database and 100 articles from The Times Digital Archive. Since the British Library Newspapers Parts 1 and 2 cover mostly regional newspapers, we thought it necessary to take a contrastive sample of 100 news article from The Times, thus representing a mainstream national newspaper 
from the chosen period. This decision was done to see if there were any stylistic differences in the lexical choices between the regional and national news texts which might have affect the way in which prostitutes and prostitution was talked about at the time, particularly since prostitution as a crime was widely sensationalised in public. The articles themselves often were a mixture of different kinds of texts, i.e. the reporters gathered information from various sources like the Police, the court records and depositions, as well as eye-witnesses, and this might have influenced the manner and style of reporting. Such differences between the two datasets were not, however, found.

Because of the vast number of news reports about prostitution at the time, it was impossible to include all available data in this case study. For this reason, the choice of the news reports included was conducted by choosing a random number of examples from each decade of the century under study. All the news coverage, i.e. only those texts labelled in the databases as 'news articles', between the time span 1800-1899 was searched for nominal references to both prostitutes (people) and prostitution (concept). The main division in the data was made between prostitutes as third person referents, and prostitution as a semantic source domain.

The main search was done in two stages. Firstly, the search word used for person reference to prostitutes was prostitute in all articles chosen for the study. The initial search word list came from our previous study (Nevala and Hintikka 2009), but was soon found to be mostly inapplicable owing to technical reasons, mainly because the poor quality of the original data (in images only) prevented the search engine from identifying certain words (e.g. in the case of whore/whom or whose and bawd/band) in many occasions. Moreover, we found that most of the terms for prostitutes in the previous study were used metaphorically rather than for actual person reference in the current dataset. The resulting articles were closely read and searched for other terms referring to prostitutes, which were eventually categorised under two main themes emerging from the textual context, social attitude and personal behaviour (see Section 4.1).

Secondly, the data was searched for conceptual metaphors with the truncated search term prostitut* so as to include all forms of both lemmas prostitute and prostitution. After the initial search the results were closely read so as to identify metaphors - instances where the lemma prostitut* is used not to denote a literal prostitute but to represent something else, usually a more abstract or intangible concept - and to discard instances of literal use which, expectedly, formed the vast majority of the search results. The results were disappointing as they turned up only instances of the verbal use of the term to prostitute. ${ }^{2}$ As a metaphorical source term, prostitut* may bear elements that render it too 'technical' for metaphor. According to Zharikov and Gentner (2002), and in keeping with the assumption that the emergence of metaphor requires a degree of terminological familiarity, technical terms do not tend to lend themselves readily to figurative uses. Therefore, a further search had to be conducted using more colloquial terms. This produced the results shown in Table 2 in Section 4.2. As stated above, the quality and technical characteristics of the collection of source material made it necessary to discard certain search terms altogether. Similarly, other search terms simply did not produce any examples of non-literal use.

The reason for looking at prostitution as the cognitive 'vehicle' rather than the 'target' is a practical and datarelated one. Although there are many different concepts that are automatically triggered in connection with PROSTITUTION (such as SICKNESS, DIRT, SIN, etc.), there is nevertheless no set of fixed source domain concepts for the target domain of PROSTITUTION that one can exhaustively look for. This means that to look for metaphors about prostitutes or prostitution is largely to be at the mercy of intuition and luck, not to mention shackled with inordinate amounts of irrelevant examples (a search term like filthy is likely to produce mostly examples of literal use). Trial searches using prostitution-related terms proper, in the hope of finding examples where literal and figurative language were being used together, proved unfruitful as even instances where there

\footnotetext{
${ }^{2}$ We have excluded all instances of the verbal use of the term prostitute because of its semantic properties, which can already have been said to be in place in the nineteenth century, namely its close synonymy with the concept of 'corruption' (in the broadest possible sense), and therefore lessened metaphorical versatility.
} 
was some tenuously metonymical adjective in connection with the concept of PROSTITUTION, it tended to be in cases where the concept was being used as the source, not the target domain.

The present material revealed two broad newspaper discourse topic areas that draw on the source domain of prostitution, namely those of RELIGION, and POLITICS. There were a handful of other, less defined topic areas but they cover a narrow field and consist of examples where prostitution-related imagery is invoked, but is non-defined and arbitrary. In the two main categories the metaphors are obviously and overtly negative and can usually be said to highlight a certain type of negative quality, or cluster of negative qualities. In order to further establish the significance of these different source domains it was necessary to look at them contextually: Are some of them found significantly more often than others? Which qualities associated with prostitution tend to become metaphorical? We ask these questions bearing in mind that conceptual metaphor patterns can be emergent and that source-target connections are, therefore, not purely conceptual but also reliant on discourse traditions and therefore context-dependent (Cameron and Deignan 2006: 674). In this article, however, we focus on a single text-type and are therefore only interested in the broad distinction between the two emergent topic areas where prostitution metaphors occur.

\section{Prostitutes and prostitution in the newspapers}

In this section, we will present examples of the news reportage concerning the person of prostitutes and the metaphors on prostitution. The terms related to prostitutes and prostitution are marked in bold, and underlined are those descriptions which further help determine the tone of reference in relation to each textual context.

\subsection{The representation of prostitutes}

News stories in general require evaluation to establish the significance of what is being told, to focus the event, and to justify claiming the audience's attention (Bell 1991: 151). The Victorian press generally used melodramatic fiction in presenting the darker sides of social life including rudimentary psychological analyses and a fascination with shocking detail (Conboy 2010: 87, Linnane 2003: 280, O'Reilly 2014: 222). Although people in the nineteenth century were fascinated by news about social and moral degradation, they were at the same time very conscious of the respectable vs unrespectable dichotomy. The growing middle class in Britain lead the change in moral sensibility, forwarding and reinforcing the Victorian values in newspapers and other public texts (Linnane 2005: 176-177). What Victorians basically wanted was "privacy for the middle classes, publicity for the working classes, and segregation for both" (Olsen 1976: 23).

As Foulkes (2003: 41) writes, prostitutes were everywhere (see also Garton 2004: 116). According to Duda (2014: 79), Victorians made a clear distinction between "a chaste passionless middle-class woman" and "an insatiable and morally corrupt fallen woman". Descriptions, such as the nineteenth-century feminist Flora Tristan's (1839), were printed as warnings for 'decent' people' not to enter the most decadent areas of London: "This neighbourhood [St. James's] is almost entirely inhabited by prostitutes and people who live off prostitution; it is courting danger to go there alone at night. It was a hot summer evening; in every window and doorway women were laughing and joking with their protectors. Half-dressed some of them naked to the waist, they were a revolting sight" (Foulkes 2003: 41). Sometimes it was more a matter of what was left out, as for example, when the more respectable newspapers refused to cover the debates held around the Contagious Diseases Acts (1864-1869) because of their sensational nature and relatedness to prostitution (Diamond 2003: 110-111).

The medium of newspapers naturally affects the language used. Whereas men are, for example, usually portrayed as being the agents of their crimes, women are often seen as objects of male influence or coercion (Mayr and Machin 2012: 135). News features on crimes committed by women tend to focus on the incapability of women to commit a crime on their own, and although much of the nineteenth-century 
reporting on prostitution still worked on the evil vs good dichotomy (here, 'social attitude'), the representations of female prostitutes were also based on their type of behaviour and level of attractiveness (here, 'personal behaviour').

A more detailed description of the data on the third-person nominal reference to prostitutes can be seen in Table 1. As already mentioned in Section 3, the two major themes emerging from the data were social attitude (e.g. relating to scandal, social evil, immorality, infestation) and personal behaviour (e.g. relating to obscene language, drunkenness, disorderly conduct, indecency).

Table 1. Nominal terms referring to prostitutes in the data.

\begin{tabular}{|c|c|c|c|c|c|c|c|c|c|c|}
\hline & Prostitute & Woman & Girl & Female & Creature & Person & Character & Outcast & Other & Total \\
\hline $\begin{array}{l}\text { Social } \\
\text { attitude }\end{array}$ & 188 & 318 & 96 & 8 & 24 & 8 & 39 & 16 & 78 & 775 \\
\hline $\begin{array}{l}\text { Personal } \\
\text { behaviour }\end{array}$ & 333 & 242 & 141 & 8 & 8 & 28 & 17 & 0 & 534 & 1,122 \\
\hline Total & 521 & 560 & 237 & 16 & 32 & 36 & 56 & 16 & 423 & 1,897 \\
\hline
\end{tabular}

When we look at individual terms, we can see that in addition to the word prostitute, woman is the most typical term in the social behaviour category, making it also the most frequently used term in the data. In general, the terms range from those referring to a female human object (prostitute, woman, girl, female), an evaluated object (creature, outcast), and an unevaluated human object (person, character; other: i.e. prisoner, party, alien). The interpretation of the terms is heavily dependent on the context. For example, in the present data, expressions like girl, outcast, and creature have proved not only to be influenced by the textual context in which they occur, and of whom they are used, but also on the socio-historical background to the time when they are used. The nominal terms in the social attitude category often occur together with attributes like ill-fame, disgusting, obscene, and even swarming with vermin. The category of personal behaviour includes adjectives like repulsive looking, of the poorest condition, drunken, and riotous.

In the data, these two main themes are also often used together. Prostitutes are described as filthy, both as deriving from the notion of filth (i.e. social attitude of 'the scum of the earth') and as from actually being dirty or behaving in a dirty manner (i.e. personal behaviour). Example (1) shows one of the most negative references in the material. The excerpt comes from a news article reporting on yet another social discussion about the abolishing of prostitution. Prostitutes are referred to as degraded prostitutes and filthy, dirty creatures, who commit the most horrible practices. The words terrible, shameless, and indecorous are associated with prostitutes, who are also mentioned as being foreign women. The common negative attitude against these evil creatures very much draw from the images of the Bible and depict prostitutes as nonhuman entities.

They had it on the testimony of Sir R. Mayne that the increase of prostitution in the parish was terrible. [...] They had no means by which to take the initiatory steps, unless they resorted to the most horrible practices, or associated themselves with degraded prostitutes - filthy, dirty creatures - who would give evidence of the nature of the house, otherwise the prosecution must fail. They were aware that until happier social influences prevailed these things would be part of the social scale. All they wanted to suppress was the outward and shameless manifestation of prostitution. The foreign women in the Haymarket were the most glaring part of this evil in their indecorous harlotry. (The Morning Post, 11.3.1858) 
In Example (2), the description is mostly based on attributes relating to personal behaviour. The woman has been accused of stealing a book from her client (an unlawful act), a matter which she denies by telling the police constable that, owing to his lack of money, the client gave her the book as a payment of her services. The rather empathetic tone of the description is set already at the beginning of the story: a prostitute of the poorest condition who pursues her wretched calling in the streets makes, however, an account of the events with much apparent sincerity. Stealing and other dishonourable acts are, of course, stereotypical behaviour for prostitutes, whereas being honest is not.

A prostitute of the poorest condition, who gave the name of Deacon, was charged at the Westminster Police Court, with unlawfully having in her possession a large and very handsomely illustrated Book of Common Prayer. [...] When before the magistrate, she repeated, with much apparent sincerity, a statement that she had made to the constable on her way to the station, that while pursuing her wretched calling in Oxford-street, she was accosted by a gentleman, who treated her with wine, and afterwards accompanied her to a house, in that neighbourhood, on leaving which, discovering he had no money in his pocket, he gave her the book in question rather than be "dishonourable". (The Sheffield Daily Telegraph, 18.6.1855)

Many of the features about prostitutes, and particularly about the crimes they had committed, can be considered basic news. In (3), three disorderly prostitutes have been charged with behaviour typical of the women of the trade. In addition to stealing, fighting and using very loud - and foul - language are associated with prostitutes: having no sense of 'good manners' is considered another characteristic of people of the social margins.

3)

\section{DISORDERLY PROSTITUTES.}

Dinah Dixon, Ellen McDonald, and Mary Mullen, prostitutes, were charged by Inspector Anderson with fighting and shouting and using very bad language in Collingwood Street, early this morning. They were each committed for one month. (Shields Gazette and Daily Telegraph, 18.10.1871)

Disorderly conduct also includes drunkenness, whether or not it leads to general mayhem. The next example is an account of a court case against a proprietor who allowed prostitutes into his public establishment, together with several sailors. The language in the excerpt is typical of court proceedings at the time. Phrases like persons of notoriously bad character, parties referred to, and persons of the class referred to are repeated in the text several times, all used in reference to prostitutes and the lowest social class they belong to. What is interesting in this example is that the licensed victualler is defended by the law: if these notorious customers are able to conduct themselves properly, he has to let them into the premises and serve them.

James Cook, publican, Hanover-street (opposite the Sailors' Home) was summoned yesterday before Messrs. Stilt and Jeffery for allowing persons of notoriously bad character to assemble upon his premises. [...] Witness went again an hour subsequently, and then found in the house twelve prostitutes and several sailors. [...] He pointed to the manager that the females were prostitutes. - Mr. Cobb contended that as long as the parties referred to conducted themselves properly a licensed victualler was bound to serve them. [...] Licenced victuallers were bound to supply these persons with refreshments so long as they conducted themselves properly. If the licensed victualler permitted drunkenness or disorderly conduct, that was specially provided for; but if persons of the class referred to conducted themselves properly, the landlord was bound to supply them, and if he refused he would lay himself open to an action. (The Liverpool Mercury, 16.9.1865) 
Another passage reporting a court case can be seen in Example (5). Here, the prostitute in question is referred to with the term girl. This word was mostly used of the youngest women of the trade, as well as in instances in which the prostitute was objectified or victimised in some way. In this case, the accused has been witnessed to have been with a more experienced prostitute, and therefore suspected ... of evil. Instead of social attitude, the account concentrates on her personal behaviour: in addition to being impudent, she was noisy and very violent.

5) The charge was made that she was "a common prostitute, and so suspected of evil contrary to the charter and the statutes of the University in that case made and provided." The girl, who was undefended, pleaded "not guilty." Mr. H. G. Fuller, M. A., of Peter-house, an additional proproctor, said he was in St. Andrews-street on the previous night about 10 o'clock, and saw the prisoner walking with another girl. He suspected her of evil because he has seen her loitering in the streets in company with a known prostitute at a late hour. He had warned the prisoner on three occasions. Twice when he spoke to her she was noisy, and on the third occasion impudent. .On being arrested the prisoner was very violent. (The Times, 30.5.1892)

\section{MURDEROUS ASSAULT ON A PROSTITUTE AT CHESTERFIELD.}

On Saturday a man named German Vardy committed a most unhuman assault on a prostitute, named Elizabeth Eppison, alias "Darkey Liz," who he had been enhabiting with, and who lives in Whealdon lane, Chesterfield. The man Vardy had imbibed rather too much beer, a quarrel ensued, and he knocked the girl down and punched her in a most brutal and ferocious manner, breaking her arm. She was conveyed to the hospital, at the Union, where she lies in a dangerous state, and the opinion of the doctor is, that if she gets better, she will be a cripple for life. The man Vardy was brought up at the Borough Police Court on Monday, and remanded. (The Derbyshire Times, 30.5.1868)

The last example (6) deals with a prostitute being a victim of a crime. Again, the term girl is used, this time not to describe a particularly young woman, but actually a very experienced one in her trade. The gravity of the assault is described as murderous, unhuman, brutal, and ferocious. The readers' sentiments side with the victim, who, despite being a common prostitute, is in a dangerous state and may be a cripple for life. This kind of turning of 'the fiend' into 'an angel' is very typical of the news where the prostitute is depicted as an object instead of the agent of an act of violence or otherwise bad behaviour (cf. Nevala 2016). Whereas in Example (1) the prostitutes were described as filthy, dirty creatures, in this case it is the person who assaults the prostitute that is dehumanised.

\subsection{Prostitution in metaphor}

The image of the dirty, corrupt prostitute is an obvious candidate for metaphoric source domain in fulminating discourses on any form of corruption or degradation. While it is also found in fairly mundane contexts, it comes into full fruition in the more emotive discourses that employ deliberately persuasive language. Topic areas may vary but the tone in the contexts where prostitution metaphors are found is invariably that of condemnation. The target concepts tend to center around qualities such as deceitfulness, ugliness, corruption, or putridity.

As stated in Section 4.1, melodramatic fiction and style were very much the bread and butter of the Victorian press. Language was designed to arouse emotional responses both in terms of its contents and its form. Metaphor was - and continues to be - well suited for these purposes and its use was fairly prolific. This may have to do with the understanding, subscribed to in the tradition of classical rhetoric that one of the effective ways to persuade an audience is by turning the auditors - or, as in the present case, readers - into spectators 
by adding figures of speech which the audience can see with their minds' eye: to see is to believe, and, eventually, to see is to understand (Skinner 1996: 182, Phillips and McQuarrie 2004: 114, Moran 1996: 10). In nineteenth-century (and earlier) discourses the emotional was regularly and openly evoked in order to get a point of view across to the public. At the same time, orderly and systematic metaphorical networks provided a cognitively salient structure for thinking and reasoning, and extended metaphors were common even in mainstream, unmarked public discourses (Hintikka 2013: 140). What Tillyard (1943: 107) calls the Elizabethans' "passionate love of ceremony" can be seen to still affect the Victorian era, at least from the perspective of systematic metaphoric correspondences in fairly unmarked forms of discourse.

The concept of PROSTITUTION does not exhibit a particularly notable metaphor productivity: three metaphorically used terms out of a cornucopia of related words and expressions does not seem like much for a source domain so potentially highly charged and emotively captivating (for further discussion on the role of emotivity in metaphor, see e.g. Musolff 2004, Harris 1998, Charteris-Black and Musolff 2003). ${ }^{3}$ However, the metaphorical strength of the domain, amply makes up for its low productivity and makes a fair case for the cognitive embeddedness of the concept of prostitution within the matrix of nineteenth century morality.

Table 2 shows the numbers and distribution of the source domain uses of the concept of prostitution in the present material. The terms that were used metaphorically were harlot, bawd, and, to a lesser extent, whore. The context-level categorisation into political and religious domains emerged from the material and is, in part, blurred in the middle. This division was made purely by the subject-matter involved in each case, and the parameters are, for the most part, straightforward enough to justify the particular categorisation. Any political or social context without reference to religious authorities or issues pertaining to Christian morality have been counted as instances of political contexts, while any that involve critique or praise of religious authorities, appeals to Christian values, or commentaries on state or other religion have been counted as instances of religious contexts.

Table 2. Prostitution terms in metaphorical use in the material.

\begin{tabular}{|c|c|c|c|c|}
\hline & harlot & whore & bawd & Total \\
\hline Political & 181 & 11 & 96 & 288 \\
\hline Religious & 132 & 12 & 54 & 198 \\
\hline Total & 313 & 23 & 150 & 486 \\
\hline
\end{tabular}

The table shows the absolute number of times each term is used metaphorically in the two different context types. The political contexts seem to attract prostitution metaphors clearly more than the religious ones, with harlot as the most frequent term in both context types. What is significant from our viewpoint is the differences in extendedness between the three terms: while whore and bawd most typically occur alone in a passage, harlot is more often a part of an extended metaphor, accompanied by supportive adjacent-domain terms, such as filthy, drunken, etc. This is likely to be due to the highly figurative and specialised status of the term harlot which is, even in nineteenth-century discourse, hardly ever found in literal contexts. This type of semantically specialised term is likely to attract appendices and elaborations that corroborate its figurative status further.

\footnotetext{
${ }^{3}$ The other related terms used in searches were slut, fallen woman, hooker, courtesan, madame, temptress, doxy, moll, night walker, nymph*, and tramp (cf. Nevala and Hintikka 2009).
} 
Example (7) is illustrative of a central use of (extended) prostitution metaphors. The negative concept of HARLOT is supported by the common collocate adjective ugly and the further elaboration she paints ('applies makeup'). This invokes the immorality of the deceitful sexuality of the inwardly ugly prostitute, making an analogy between the inherent deceit seen to be present in prostitution and in 'falsehood'.

7) "The world is for them and the world's law;" but for sound understandings who suffer, and for sound understandings who witness so much suffering by others, to talk of the happiness of the country, is to exhibit one of the most melancholy results of the debasing effect upon intellect, which a hand-in-glove intercourse with systematic trickery, deception, disguise and false colouring, always ultimately ensues. Falsehood is an ugly harlot, but she paints; and if continually in her company, we begin to think that it is Truth who is unnatural. How many in Parliament are in this predicament? (The Examiner, 17.3.1822)

Example (8), similarly, draws on the insincerity seen to be germane to prostitution and prostitutes. Here, the target of deceit is the self, i.e. to fool oneself was to play a whore's trick on oneself.

8)

How true is our common law maxim, that no man is an upright judge in his own cause; how truly and prettily said by the French, "La Nature se pipe;" nor less truly, though more grossly in English, "Nature's her own Bawd." (The Examiner, 3.1.1819)

Example (9) is an extended metaphor and an illustrative instance of an emotively charged use. Here, we find a cluster of related terms and phrases that together form a nearly picture-like image of prostitution: "religion fair and pure, [...] dressed her like a harlot." The terms fair and pure pertain to the field as the antitheses of the corruption of prostitution, and the allusion to dressing up as something (other/finer than what one really is) is also germane to the concept of deceit and corruption.

9) Ireland was emphatically called the "sister" country, and it behoved them to use her tenderly (hear.) Where was the man who would not resent an injury done to a brother, but what greater affront could be given than to offer an insult to a sister? (cheers.) Here then has the sister of England being maltreated, nay, even slaughtered before their eyes, and would they not rush to her defence? (we will, we will.) Was it not disgusting in the extreme to know that the sons and daughters of Ireland were being murdered at the 'instigation' of a set of men who called themselves ministers of God - who found religion fair and pure, but who had dressed her like a harlot (much cheering). (The Poor Man's Guardian, 3.11.1832)

Example (10) also employs supporting terminology, albeit not from the domain of prostitution. Here, the imagery is that of a fallen tyrant who fails to see their state of debauched disgrace and still attempts to hold on to power. With phrases like "so long drunk with the blood of other nations", "reels and totters with her own inanity", and "glares upon us with her red eyeballs", an image is created of not only futile pomp but, what is more, utter indignity, a quality also closely associated with prostitution. Example (11) can be said to be a less elaborate version of similar imagery use.

10) 'England for centuries has been bullying and bribing the world;' 'her insolence is astounding.' 'In the Pacific, in the Atlantic, on the Isthmus, everywhere, that haggard voluptuary, Great Britain, who has been so long drunk with the blood of other nations that she now reels and totters with her own inanity, glares upon us with her red eyeballs, and bids us depart.' (Reynolds's Newspaper, 6.7.1856)

11) The many victories that were achieved by Lord Beaconsfield, and the confidence that the Conservatives and the people placed in him, were won by his determination in principle and firmness of purpose, and the same confidence and the same trust is placed in his successor the present leader of the Conservatives in the House of Commons - in that good fight in which he has to engage, wherein the drunken harlot of British democracy - armed, for the nonce, with 
authority - seeks to overpower the law of order, and to unbar the prison gates of crime for the emancipation of the murderer and the robber. (Trewman's Exeter Flying Post or Plymouth and Cornish Advertiser, June 29.6. 1881)

Example (12) employs, in addition to the central metaphorical element (the Whore of Babylon) a single additional, cognitively related item in close proximity (flirtation) to form an easy-to-grasp image of a desired kind without the kind of extended elaboration found in Example (10).

He did more; he visited the Junta, went through all the routine of etiquette and politics, made a speech about reform, took his glass after dinner, and religiously toasted the Pope! (Hear, hear!) It was surprising indeed, to see him so soon returning after his flirtation with the "Whore of Babylon," at Cadiz! (Cobbett's Weekly Political Register, 27.1.1810)

Most of the examples above show that the vocabulary involved in the domain of prostitution by far exceeds the core group of lexemes used in the original searches. Terms such as flirtation, drunken, reel, and totter, all play supporting parts in the creation of the desired imagery but are, of course, too broad semantically to be associated with prostitution alone. They do, however, within these contexts, extend the prostitution metaphor and thus provide it with the kind of narrative structure referred to in Section 2.2. For the most part, these extensions are made into the realms of aesthetics and morality: the metaphorical prostitutes are mostly made out to be filthy and drunken and/or ugly and grotesquely painted. These seem to be the qualities, then, that mostly transcended the literal as perhaps the most poignant and the most damning qualities found in women who did not fit the contemporary ideal of female virtue.

There is always a risk in data-driven study of metaphorical language that some terminological pockets remain unfound due to the limitations of researcher intuition. However, as the aim of this study is not to be comprehensive but, rather, illustrative, the vocabulary chosen for searches seemed to be satisfactory enough for forming a general idea of the kind of role played by prostitution in metaphor in nineteenth-century press.

\section{Detestable yet victimised: conclusions}

As compared to the results from our previous study on earlier periods (Nevala and Hintikka 2009), the nineteenth-century data seem to show prostitutes as both detestable and victimised. According to Garton (2004: 117-119), the Victorian attitude towards prostitution was dichotomous: social reformers saw prostitutes as lowly and diseased, morally corrupt themselves, while others argued they were the victims of upper class corruption. On the one hand, we are talking about moral degradation, on the other hand, prostitution is seen as women's work, brought on by the Victorian perspective of linking the social margins to the working class.

Our study corroborates this view: if we look at the reference to prostitutes alone, two prominent themes can be detected in the public discussion in newspapers, social attitude and personal behaviour. The theme of social attitude is associated with such issues as scandal, social evil/immorality, and infestation. In language use, prostitutes are often described with attributes like ill-fame, disgusting, obscene, and even swarming with vermin. The theme of personal behaviour is associated with such traits as obscene language, drunkenness, disorderly conduct, and indecency. These characteristics are emphasised by the use of adjectives like repulsive looking, of the poorest condition, drunken, and riotous. The most used nominal term here is prostitute: in the most negative descriptions, prostitutes are pictured as non-human entities or animal-like creatures. The notion of judgment is prevalent in the descriptions of prostitutes, evaluated through their person and actions. As already mentioned in Section 2.1, judgment concerns here also ethic evaluation as a dimension of social sanction.

In basic news stories, e.g. when reporting about prostitutes being arrested or convicted, they are most often evaluated in terms of objectivity (i.e. not many negative labels are used). In these cases, the description of a 
prostitute is at its closest to the idea of a working woman. The most often used terms in the data are prostitute and woman. On the one hand, the label woman is most common in the social attitude category, which seems to have been mostly used in contexts where the writer wants to emphasise the corruption of the female gender in particular. The term prostitute, on the other hand, appears most prominently in the personal behaviour category, and is typically used in evaluatively more neutral news reports. The most evaluative, or should we rather say, compassionate, reporting involves a situation in which a prostitute is a victim of a crime or some other hurtful act, such as an assault. In these cases, they are mostly referred to with the term girl, and with attributes like poor, sad, and in a dangerous state. It seems that the vulnerable role of a victim surpasses the detestable role of a common prostitute, and the reference almost resembles 'angel-naming' (for further discussion, see Nevala 2016).

From the CMT standpoint, the prostitute as object of compassion is more difficult to discern. All the metaphors found in the material draw from the negativity seen as inherent in prostitution and prostitutes. This is accentuated by the frequent personification of states or political institutions as prostitutes, whose lamentable behaviour or appearance is referred to in the metaphor. Frequent elaboration and the use of extended metaphor suggests a notable commitment to the prostitution metaphor as a thought structuring construct whose appeal to the readership was not questioned.

As is consistent with the rationale of metaphor use in general, the terminology employed is fairly limited to the core (i.e. the most immediately available and largely intelligible) vocabulary of the domain (Hintikka 2013: 56-57). Within the three metaphorically used terms, harlot stands out as the most frequent in metaphor. This is also the term with most attested extended uses in the present material. In fact, the term is rarely found in literal use, suggesting an ongoing semantic narrowing process that may, in time, render its use in literal contexts impossible.

If we look at the core definition for 'prostitute', the idea of trading sexual favours for money will suggest itself first and foremost. However, it is the accompanying, implicit qualities assumed to be shared by prostitutes a lack of hygiene, diseasedness, ugliness, grotesque use of 'paint', brazenness and drunkenness - that make it into metaphoric use. The contexts in which prostitution is evoked metaphorically rarely deal with 'trading' in any form, either moral, political, or religious, but rather more often highlight the grotesque, the ridiculous or the unaesthetic of a given situation.

\section{References}

\section{Primary sources}

19th century British Library newspapers database, British Library newspapers parts 1 and 2: 1800-1900. http://www.gale.com/c/british-library-newspapers-part-i (accessed 18 May 2015, 6 June 2015; 18 August 2016 and 19 August 2016).

The Times digital archive, 1785-2011. http://www.gale.com/c/the-times-digital-archive (accessed 20 October 2016).

\section{Secondary sources}

Allport, Gordon. 1986. The language of prejudice. In Paul Escholz, Alfred Rosa \& Virginia Clark (eds.), Language awareness, 261-270. New York: St. Martin's Press.

Bednarek, Monica. 2006. Evaluation in media discourse: Analysis of a newspaper corpus. London: Continuum. 
Bednarek, Monica \& Helen Caple. 2012. News discourse. London: Bloomsbury.

Bell, Allan. 1991. The language of news media. Oxford: Blackwell.

Cameron, Lynne \& Alice Deignan. 2006. The emergence of metaphor in discourse. Applied linguistics 27(4). 671-690.

Charteris-Black, Jonathan \& Andreas Musolff. 2003. 'Battered hero' or 'innocent victim'? A comparative study of metaphors for euro trading in British and German financial reporting. English for special purposes 22. 153176.

Conboy, Martin. 2010. The language of newspapers: Socio-historical perspectives. London: Continuum.

Diamond, Michael. 2003. Victorian sensation, or the spectacular, the shocking and the scandalous in nineteenth-century Britain. London: Anthem Press.

Duda, Bożena. 2014. The synonyms of fallen woman in the history of the English language. Frankfurt am Main: Peter Lang.

Foulkes, Nick. 2003. Scandalous society: Passion and celebrity in the nineteenth century. London: Abacus.

Garton, Stephen. 2004. Histories of sexuality: Antiquity to sexual revolution. London: Routledge.

Gentner, Dedre. 1983. Structure-mapping: A theoretical framework for analogy. Cognitive science 7. 155170.

Harris, Jonathan Gil. 1998. Foreign bodies and the body politic: Discourses of social pathology in early modern England. Cambridge: Cambridge University Press.

Hintikka, Marianna. 2013. The well-being of the body as metaphor for society and mind. A corpus-based comparison of early modern and present-day English. Helsinki: Modern Language Society.

Kövecses, Zoltán. 2000. The scope of metaphor. In Antonio Barcelona (ed.), Metaphor and metonymy at the crossroads: A cognitive perspective, 79-92. Berlin: Mouton de Gruyter.

Lakoff, George. 1987. Women, fire and dangerous things: What categories reveal about the mind. Chicago: University of Chicago Press.

Lakoff, George \& Mark Johnson 1980. Metaphors we live by. Chicago: University of Chicago Press.

Linnane, Fergus. 2003. London: The wicked city. London: Robson Books.

Linnane, Fergus. 2004. London's underworld: Three centuries of vice and crime. London: Robson Books.

Lovejoy, Arthur O. 1936. The great chain of being. A study of the history of an idea. New York: Harper \& Row.

McEnery, Anthony \& Helen Baker. 2016. Corpus linguistics and 17th-century prostitution. London: Bloomsbury.

Martin, James R. \& Peter R.R. White. 2005. The language of evaluation: Appraisal in English. Basingstoke: Palgrave Macmillan.

Mayr, Andrea \& David Machin. 2012. The language of crime and deviance: An introduction to critical linguistic analysis in media and popular culture. London: Continuum.

Moran, Richard. 1996. Artifice and persuasion: The work of metaphor in the rhetoric. In Amelie Oxenberg Rorty (ed.), Essays on Aristotle's rhetoric, 385-398. Berkeley: University of California Press. 
Musolff, Andreas. 2004. Metaphor and political discourse: Analogical reasoning in debates. Basingstoke: Pelgrave Macmillan.

Nevala, Minna. 2016. Solidarity in evaluation: The portrayal of victims and criminals in late nineteenthcentury newspapers. In Minna Nevala, Ursula Lutzky, Gabriella Mazzon \& Carla Suhr (eds.), The rhetoric of character, face and identity construction from early modern to present-day English. Studies in Variation, Contacts and Change in English 17.

Nevala, Minna \& Marianna Hintikka. 2009. Cider-Wenches and High prized Pin-Boxes: Bawdy terminology in 17th- and 18th-century England. In Roderick W. McConchie, Alpo Honkapohja \& Jukka Tyrkkö (eds.), Selected proceedings of the 2008 symposium on new approaches in English historical lexis (HEL-LEX 2), 134-152. Somerville, MA: Cascadilla Press.

Olsen, Donald J. 1976. The growth of Victorian London. London: Holmes \& Meier.

O'Reilly, Carole. 2014. 'Dirt, death and disease': Newspaper discourses on public health in the construction of the modern British city. Journal of historical pragmatics 15(2). 207-227.

Phillips, Barbara J. \& Edward F. McQuarrie. 2004. Beyond visual metaphor: A new typology of visual rhetoric in advertising. Marketing theory 4 (1/2). 113-136.

Rakova, Marina. 2003. The extent of the literal: Metaphor, polysemy and theories of concepts. London: Basingstoke Macmillan.

Skinner, Quentin. 1996. Reason and rhetoric in the philosophy of Hobbes. Cambridge: Cambridge University Press.

Stubbs, Michael. 2001. Words and phrases: Corpus studies of lexical semantics. Oxford: Blackwell.

Svanlund, Jan. 2007. Metaphor and convention. Cognitive linguistics 18(1). 47-89.

Tabbert, Ulrike. 2015. Crime and corpus: The linguistic representation of crime in the press. Amsterdam: John Benjamins.

Tilliyard, E. M. W. 1943. The Elizabethan world picture. London: Penguin Books.

Veale, Tony. 2003. Systematicity and the lexicon in creative metaphor. Proceedings of the ACL 2003 workshop on lexicon and figurative language 14. 28-35.

White, Peter R.R. 2001. Appraisal outline. http://www.grammatics.com/appraisal/ (accessed 31 August 2015).

Zharikov, Sergey S. \& Dedre Gentner. 2002. Why do metaphors seem deeper than similes? In Wayne D. Gray \& Christian D. Schunn (eds.), Proceedings of the twenty-fourth annual conference of the cognitive science society, 976-981. Fairfax, VA: George Mason University. 